\title{
The investigation of a new monitoring system using leveling and GPS
}

\author{
M. Nojo ${ }^{1}$, F. Waki ${ }^{2}$, M. Akaishi ${ }^{3}$, and Y. Muramoto ${ }^{4}$ \\ ${ }^{1}$ Godo Shigen Co., Ltd \\ ${ }^{2}$ Nihonn Tennen Gas Co., Ltd \\ ${ }^{3}$ Ise Chemicals Co., Ltd \\ ${ }^{4}$ Kanto Natural Gas Development Co., Ltd \\ Correspondence to: M. Nojo (m.nojo@ godoshigen.co.jp)
}

Published: 26 November 2015

\begin{abstract}
We installed GPS stations for monitoring of land subsidence of Kujukuri Plain in Chiba prefecture in 2003, and have been monitoring since then. In this paper, we discussed a data processing method capable of reducing noise in data collected by the GPS stations. Also, we compare the accuracy of leveling and GPS, and collected basic data for establishing a new monitoring system based on the combination of leveling and GPS.
\end{abstract}

\section{Background}

In Chiba prefecture,Japan, eight companies have exploited natural gas in Southern Kanto Natural Gas Field, which is a deposit of natural gas dissolved in water. In particular, the Kujukuri district has good gas production ratio, therefore natural gas with formation water is mainly produced there.

Land subsidence in this area was found in the late 1960s. The eight companies in this area have been making efforts to control land subsidence and also have concluded the subsidence prevention agreement with the local government. Although land subsidence in recent years has been reduced in many areas, land subsidence of more than $10 \mathrm{~mm}$ per annum has been observed in some places. The eight companies currently operate addressing environmental problems including land subsidence through the Environment Committee of the Japan Natural Gas Association Keiyo Natural Gas Association (hereinafter referred to as the Environment Committee). The monitoring and observation working group works under the commitee.

\section{Result summary}

\subsection{The installation of six GPS stations and subsequent monitoring}

Natural gas with formation water is mainly produced in the Kujukuri district. The companies conduct leveling surveys twice a year. Although data from leveling surveys is accurate, it is only conducted perioducally. On the other hand, GPS system can collect location infomations of the GPS station continuously. The WG installed three GPS stations in and near the Kujukuri district in 2003, and an additional three stations in that area in 2008. Land subsidence has been monitored including GSI GPS (Fig. 1). To analize GPS data, the WG regards the Ohara station (GSI GPS) as the base station (refference point), because there is a reffernce point of leveling in Ohara near the Ohara station. The analysis software used Bernese ver 4.2. A monitoring data result in GPS stations which was established in WG is shown in Fig. 2.

\subsection{The smoothing of the GPS data which used a trend model}

Data observed in the GPS stations often includes abnormal values due to noise. The WG has smoothed the data with a 10-day moving average. However, even if the data includes abnormal values, the moving average system calculates an 


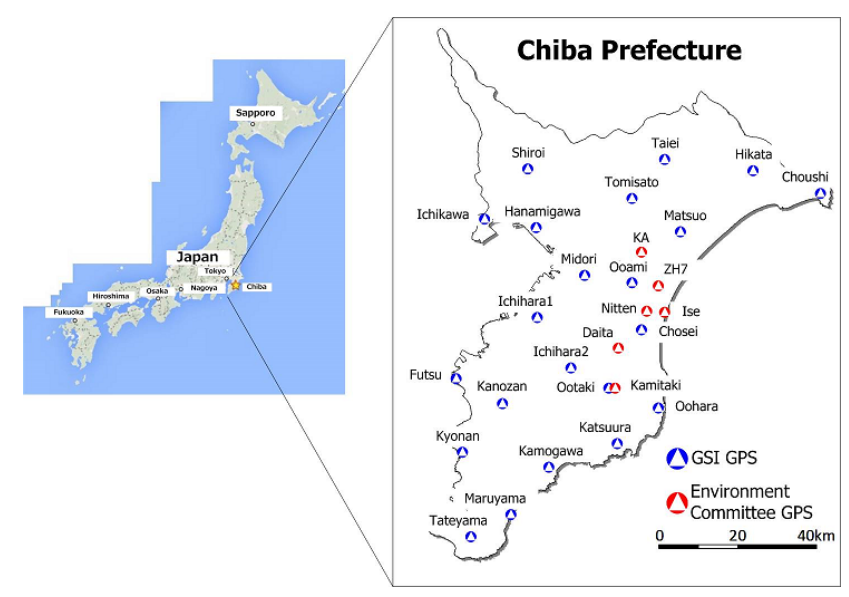

Figure 1. GPS station in Chiba Prefecture.

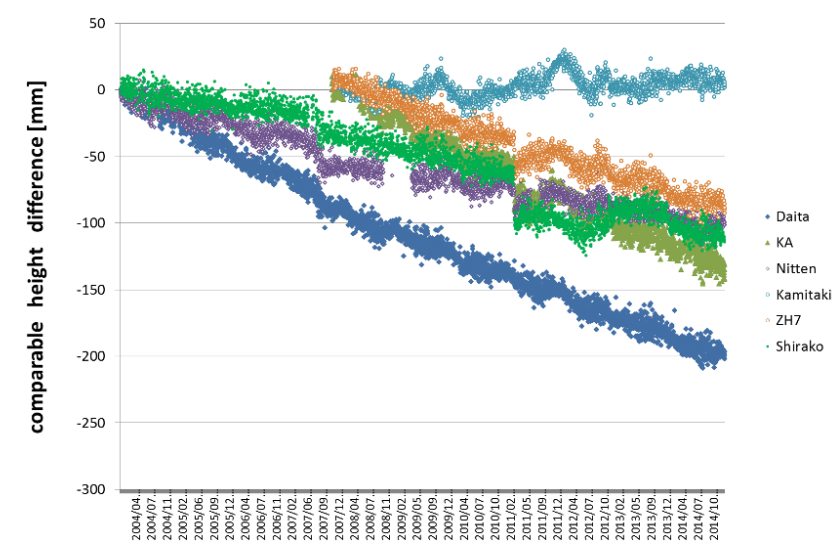

Figure 2. GPS observation result.

average of the whole data, and as a result, a calculated value may not represent the trend. To solve this problem, the WG smoothed the data with the trend model used for inversion analysis. It supposed that the time-series data followed an auto regression model and it implemented an anti-jaggy by Kalman filter. We consider the result is more reasonable than the observational data and the 10-day moving average.

\subsection{The accuracy comparison of the leveling and the GPS data}

To promote the utility of monitoring of land subsidence by the GPS stations, it is necessary to check accuracy of the observation data collected from the GPS stations. The WG conducted leveling survey between the two GPS stations every month for a total of six times between 1 June 2013 and 1 Norvember 2013, to check the accuracy by comparing leveling data with the data from the GPS stations.

Two fields inside the development area of natural gas were selected for the testing. Field 1 (Kamitaki district) is $12 \mathrm{~km}$ from the Pacific Ocean, and the relevant two GPS stations are separated by a distance of approximately $1.3 \mathrm{~km}$ in the east-
Table 1. GPS analysis conditions.

\begin{tabular}{ll}
\hline Analytical method & Static relative positioning \\
Baseline analysis software & Bernese ver 4.2 \\
Base station & GEONET Ohara \\
Analysis range & GPS station in or near Chiba Prefecture \\
Ephemeris & IGS precise ephemeris \\
\hline
\end{tabular}

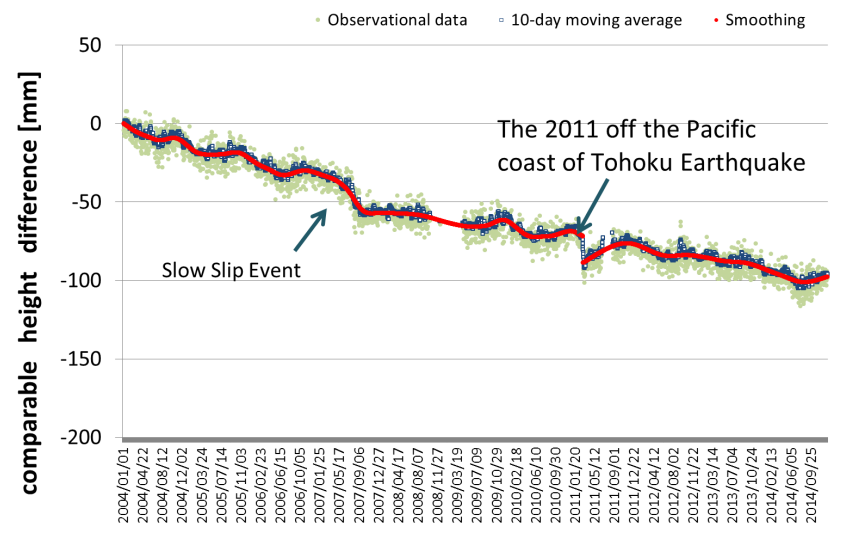

Figure 3. GPS smoothing result.

west direction. Field 2 (Daita district) is located in the hill area $10 \mathrm{~km}$ north of the Field 1, and the relevant two GPS stations are separated by a distance of approximately $2.4 \mathrm{~km}$ in the north and south direction.

A comparable height difference between the two stations was calculated individually for GPS and leveling, based on the value observed on 1 June and the results were compared.

The comparison indicated that, the maximum difference between the GPS data and the leveling data in the Kamitaki district was comparably large at $5.7 \mathrm{~mm}$. On the other hand, the data in the Daita district showed a maximum difference of $2.4 \mathrm{~mm}$. Characteristically, Field 1 is flat near the ocean and a relatively large river and Field 2 is mountainous further from the ocean. There is a possibility that the influence of water vapor content in the surrounding areas generates the measurement discrepancies.

\subsection{The examination of the leveling network which used a GPS station as a fixed point}

The leveling data of the companies reflects the result of leveling conducted by the Chiba prefectural government. Since the Chiba prefectural government releases the leveling result more than six months after the leveling survey, there is a delay in fixing their observation values by the companies. Therefore, we discussed a method to acquire data in a short time by integrating the data collected at the GPS stations and the leveling results.

Each GPS antenna and an attached benchmark are installed on the same base. Therefore, we assume that variation measured with the GPS and the variation amount of the 
Table 2. GPS analysis conditions.

\begin{tabular}{|c|c|c|c|c|c|}
\hline \multirow{2}{*}{\multicolumn{2}{|c|}{$\frac{\text { Course of Traverse }}{\text { Observation Point }}$}} & \multicolumn{2}{|c|}{ Course of Traverse 1} & \multicolumn{2}{|c|}{ Course of Traverse 2} \\
\hline & & Kamitaki & Ootaki & Daita & Jibiki \\
\hline Coordinates & $\mathrm{E}-\mathrm{W}(\mathrm{m})$ & \multicolumn{2}{|c|}{1333} & \multicolumn{2}{|c|}{986} \\
\hline difference & $\mathrm{S}-\mathrm{N}(\mathrm{m})$ & \multicolumn{2}{|c|}{164} & \multicolumn{2}{|c|}{2200} \\
\hline GPS distance & $(\mathrm{km})$ & \multicolumn{2}{|c|}{1343} & \multicolumn{2}{|c|}{2411} \\
\hline Leveling distance & $(\mathrm{km})$ & \multicolumn{2}{|c|}{2237} & \multicolumn{2}{|c|}{2536} \\
\hline
\end{tabular}

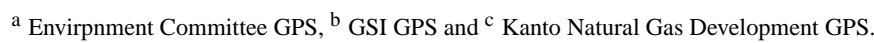

Table 3. GPS observation result.

\begin{tabular}{lccr}
\hline GPS station & \multicolumn{2}{c}{ The amount of oval } & $\begin{array}{r}\text { Quantity of } \\
\text { change }\end{array}$ \\
\cline { 2 - 3 } & \multicolumn{2}{c}{ Date } & $\begin{array}{r}\text { chang } \\
{\left[\mathrm{mm} \mathrm{yr}^{-1}\right]}\end{array}$ \\
& $\begin{array}{c}\text { Jan 2014 } \\
{[\mathrm{mm}]}\end{array}$ & $\begin{array}{c}\text { 1 Jan 2015 } \\
{[\mathrm{mm}]}\end{array}$ & \\
\hline Kamitaki GPS station & 57480.0 & 57479.6 & -0.4 \\
Daita GPS station & 69399.9 & 69387.8 & -12.1 \\
\hline
\end{tabular}
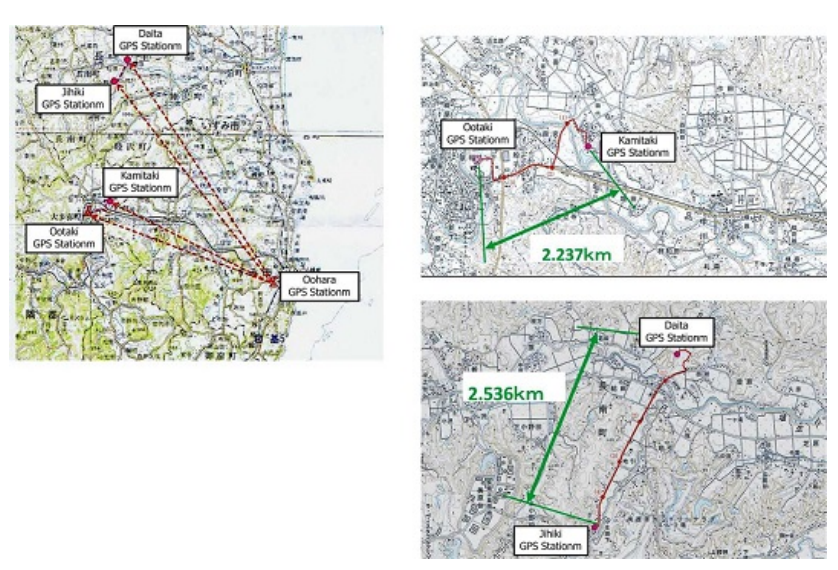

Figure 4. Course of traverse.

attached benchmark is the same. When an elevation value of the attached benchmark installed in the GPS station is acquired at any time, an elevation value of the attached benchmark can be found based on the variation amount measured with the GPS. We consider an elevation value of a benchmark near the GPS station can be acquired by leveling from the GPS-attached benchmark.

We conducted a test in the Kamitaki district and Daita district, described as the two test fields in the previous section.

\section{Test procedure}

1. A leveling network containing each GPS station and its attached benchmark is set.

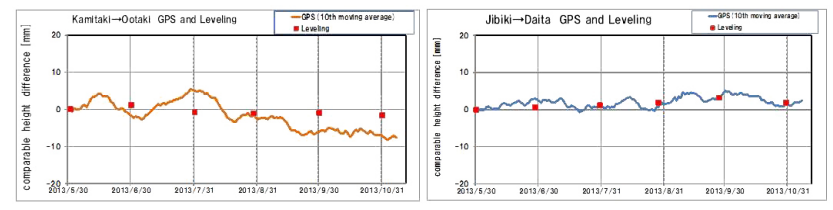

Figure 5. Comparable height difference GPS and Leveling.

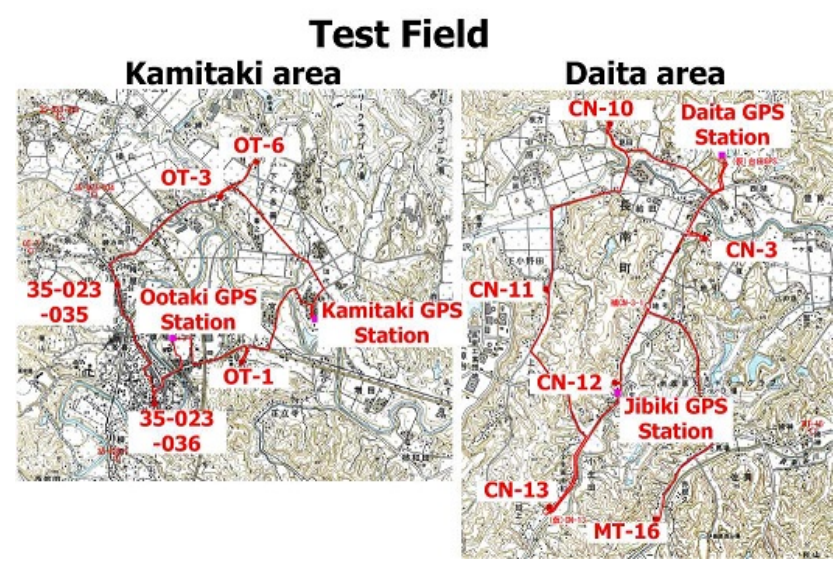

Figure 6. Test field.

2. The WG carry out surveying on 1 January 2014.

3. Based on the results of levelling measurements that the WG conducted according to the result of leveling by the Chiba prefectural government, an elevation value is given to the GPS attached benchmark.

4. The WG carry out surveying on 1 January 2015.

5. An elevation value of the attached benchmark on 1 January 2015, is determined based on the annual difference amount of the GPS station.

6. According to the attached benchmark's elevation value, an elevation value of each benchmark is calculated from the leveling survey results from the 1 January 2015 survey. 
Table 4. The change predicted value that put leveling and GPS together.

\begin{tabular}{|c|c|c|c|c|c|c|c|c|}
\hline Area & Bench mark & $\begin{array}{c}\text { Chiba prefecture } \\
\text { leveling } \\
1 \mathrm{Jam} 2014 \\
{[\mathrm{~mm}]}\end{array}$ & $\begin{array}{l}\text { WG leveling } \\
1 \text { Jan } 2014 \\
{[\mathrm{~mm}]}\end{array}$ & $\begin{array}{c}\text { Altitube } \\
\text { leve } \\
1 \text { Jan 2014 } \\
\text { [mm] }\end{array}$ & $\begin{array}{r}\text { GPS quantity } \\
\text { of change } \\
2014-2015 \\
{\left[\mathrm{~mm} \mathrm{yr}^{-1}\right]}\end{array}$ & $\begin{array}{l}\text { WG leveling }{ }^{\mathrm{b}} \\
1 \mathrm{Jan} 2015 \\
{[\mathrm{~mm}]}\end{array}$ & $\begin{array}{c}\text { Expected } \\
\text { altitube } \\
\text { level } \\
{[\mathrm{mm}]}\end{array}$ & $\begin{array}{r}\text { Expected } \\
\text { quantity of } \\
\text { change } \\
{\left[\mathrm{mm} \mathrm{yr}^{-1}\right]}\end{array}$ \\
\hline \multirow[t]{7}{*}{$\begin{array}{l}\text { Kamitaki } \\
\text { area }\end{array}$} & $\begin{array}{l}\text { Kamitaki GPS } \\
\text { attached bench } \\
\text { mark }\end{array}$ & & -9072.1 & 22253.9 & -0.4 & +0.0 & 22253.5 & -0.4 \\
\hline & OT-1 & 31326.0 & +0.0 & 31326.0 & & +9071.9 & 31325.4 & -0.6 \\
\hline & $\begin{array}{l}\text { Ootaki GPS } \\
\text { attached bench } \\
\text { mark }\end{array}$ & & -5350.9 & 25975.1 & & +3716.9 & 25970.4 & -4.7 \\
\hline & $35-023-036$ & & -5214.5 & 26111.5 & & +3852.8 & 26106.3 & -5.2 \\
\hline & 35-023-035 & & -7726.9 & 23599.1 & & +1337.6 & 23591.1 & -8.0 \\
\hline & OT-3 & & -10616.0 & 20710.0 & & -1551.2 & 20702.3 & -7.7 \\
\hline & OT-6 & & -6702.9 & 24623.1 & & +2360.1 & 24613.6 & -9.5 \\
\hline \multirow{8}{*}{$\begin{array}{l}\text { Daita } \\
\text { area }\end{array}$} & $\mathrm{CN}-12$ & 29315.6 & +0.0 & 29315.6 & & -6759.7 & 29303.4 & -12.2 \\
\hline & $\begin{array}{l}\text { Jibiki GPS attached } \\
\text { bench mark }\end{array}$ & & +209.0 & 29524.6 & & -6550.5 & 29512.6 & -12.0 \\
\hline & $\mathrm{CN}-11$ & & -104.0 & 29211.6 & & -6862.5 & 29200.6 & -11.0 \\
\hline & $\mathrm{CN}-10$ & & -6130.8 & 23184.8 & & -12889.0 & 23174.1 & -10.7 \\
\hline & $\begin{array}{l}\text { Daita GPS attached } \\
\text { bench mark }\end{array}$ & & +6759.6 & 36075.2 & -12.1 & +0.0 & 36063.1 & -12.1 \\
\hline & $\mathrm{CN}-3$ & & -9037.1 & 20278.5 & & -15795.4 & 20267.7 & -10.8 \\
\hline & MT-16 & & +6323.2 & 35638.8 & & -436.3 & 35626.8 & -12.0 \\
\hline & $\mathrm{CN}-13$ & & +11752.0 & 41067.6 & & +4993.6 & 41056.7 & -10.9 \\
\hline
\end{tabular}

${ }^{\mathrm{a}} \mathrm{CN}-12$ and OT-1 besed and ${ }^{\mathrm{b}}$ GPS attached bench mark based.

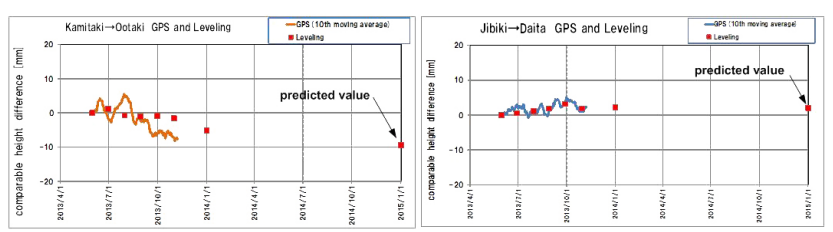

Figure 7. Comparable height difference Leveling (predicted value).

We compare the data acquired in the calculation above with the leveling results released by the Chiba prefectural government six months after the govemment's survey, and verify this test result. If the result is reasonable, we can shorten the period to fix the value after leveling from more than six months to a few months.

\section{Conclusions}

Establishment of the GPS analysis method and improvement of accuracy allow monitoring of land subsidence.

We can shorten the period to fix the value after leveling from more than six months to a few months, if the data using leveling network which used a GPS station as a fixed point are correct in comparison with the leveling results released by the Chiba prefectural government. 